\section{SEA SENSORS}

Instruments placed across the North Atlantic are starting to reveal the inner workings of a global current that mixes the oceans.

Warmer surface currents $\square$ Cold and dense deep water Cold water from the Arctic

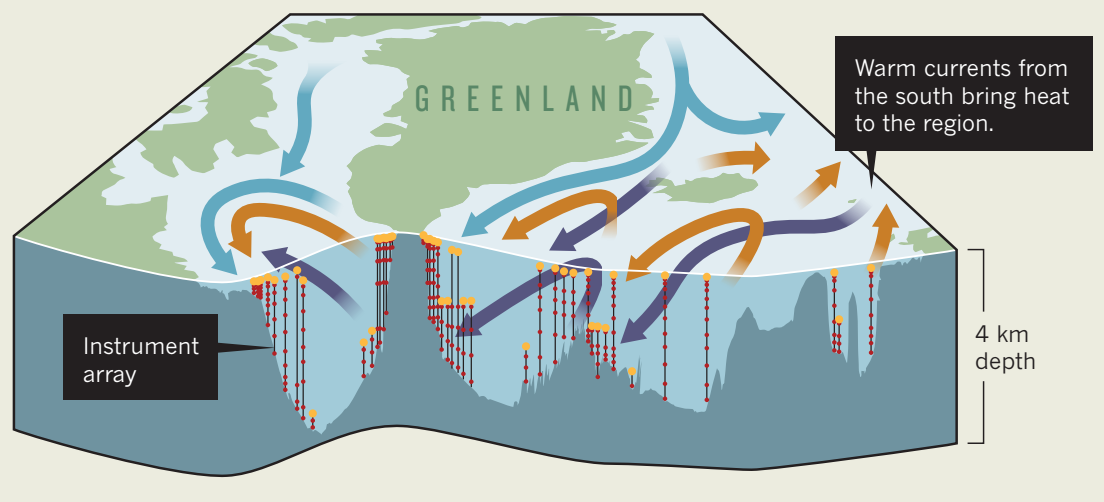

from 2009 into 2010. A study published in Geophysical Research Letters on 12 February suggests that this slowdown is part of a longer-term pattern of climate variability across the north Atlantic, and not caused by global warming (D. A. Smeed et al. Geophys. Res. Lett. http://doi.org/cknk; 2018). Teasing a potential climate-change signal out of the data could take time, in part because the natural swings in the system are so large, says lead author David Smeed, an oceanographer at the National Oceanography Centre in Southampton, UK, who is involved with RAPID.

Researchers can't fully understand this slowdown without knowing what's happening in the North Atlantic, which drives the system. OSNAP is starting to fill in that knowledge gap.

Lozier hopes that the array will eventually settle a long-standing question about what powers this system of currents: how much of the overturning circulation is driven by the winds and how much by the formation of cold, dense water that sinks into the deep sea.

Since the array started collecting data, the North Atlantic has experienced two cold winters in a row. The data indicate that the ocean formed a lot of chilly water as a result. But it remains unclear to what extent this actually had an impact on the strength of the overturning circulation.

Eventually, Lozier wants to see how the overturning circulation responds during a warmer winter that produces less cold water in the region. "We just need to keep measuring," she says.

\title{
CRISPR hack transforms cells into data recorders
}

\section{Gene-editing tool can be harnessed to give a close-up view of life's most basic processes.}

\section{BY HEIDI LEDFORD}

$\mathrm{R}$ esearchers have harnessed the popular gene-editing tool CRISPR-Cas9 to turn DNA into a sensitive recording device. The recorder can document the duration and order of events within cells - and even erase and re-record information in the same genome.

The work, published in Science on 15 February $^{1}$, joins a flock of other CRISPRbased cellular recorders that have emerged from research labs over the past few years. The hope is that such recorders could keep track of changes in gene expression, trace a cell's individual family lineage or monitor shifts in environmental conditions.

"It's clear that the genome has this enormous recording capacity," says Jan Philipp Junker, a systems biologist at the Max Delbrück Center for Molecular Medicine in Berlin. "With CRISPR, we finally have the tools to use it."

It is one of many ways in which researchers are tinkering with the machinery of CRISPRCas9 to forge new types of molecular tool. Two papers also published in Science on 15 February describe how CRISPR can be used to detect disease-causing viruses ${ }^{2,3}$.

The inspiration for the cellular recorders was the flight-data recorder found in many aeroplanes, says chemical biologist David Liu of the Broad Institute of MIT and Harvard in Cambridge, Massachusetts. "Just like a flightdata recorder records events that happen to an airplane, the cell-data recorders can be used to monitor stimuli that the cell is exposed to, or changes in the cell signalling," he says.

Researchers typically use CRISPR-Cas9 to alter DNA sequences by directing the Cas9 enzyme to cut DNA at a site dictated by the
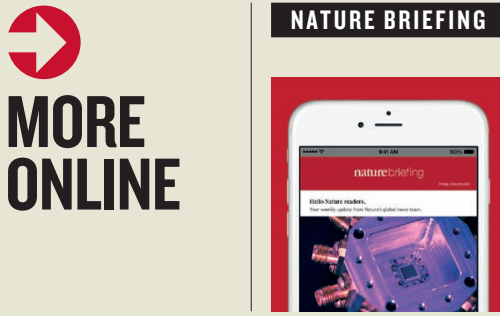

\section{NEWS}

Save time - get the daily Nature newsletter free in your inbox go.nature. com/2cxbubr
- Household chemicals such as soaps, paint and perfumes rival vehicles as a smog source go.nature.com/2hwr052

- Ocean tides could have driven ancient fish to walk go.nature.com/2gqfzwf

\section{NATURE PODCAST}

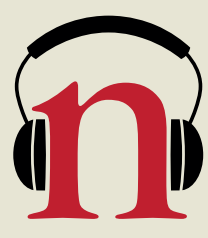

Defining adolescence; high-school researchers; and the science of teen risk taking nature. com/nature/podcast 
sequence of a short fragment of RNA, called a guide RNA. In many organisms, these DNA $\sum$ breaks are then repaired by the cell in ways that can alter the original DNA sequence.

\section{SLICE AND DICE}

Liu and his colleague, chemist Weixin Tang, also at the Broad Institute, took advantage of Cas9's DNA-slicing ability to engineer a cellular recorder using circular molecules of DNA called plasmids. Plasmids replicate inside bacterial cells, sometimes producing hundreds of copies in a single cell.

Liu and Tang altered three DNA letters in one such plasmid, so that it contained a sequence targeted by a guide RNA. They also engineered a bacterium to express Cas 9 only in the presence of a particular antibiotic, and dubbed the whole system CAMERA1.

Bacteria lack some of the DNA-repair mechanisms used by mammalian cells to fix the damage wrought by Cas9 - instead, when the plasmid is targeted by Cas9, it is degraded. Another plasmid then replicates to take the place of the lost one.

Liu and Tang put both the altered and normal plasmids into cells and measured the relative ratio of the two. The proportion of altered plasmid fell in cells that had been treated with antibiotic, because the cells had begun to degrade the altered plasmids.

The result was an unusually sensitive recorder: Liu and Tang could read out information from as few as ten bacterial cells. The magnitude of the change reflected the amount of antibiotic present, or the duration of exposure. Liu and Tang also developed methods for resetting the ratio of altered to unaltered plasmid, erasing the first recording and readying the cell to document the next event using the same set of plasmids.

They then moved on to create more

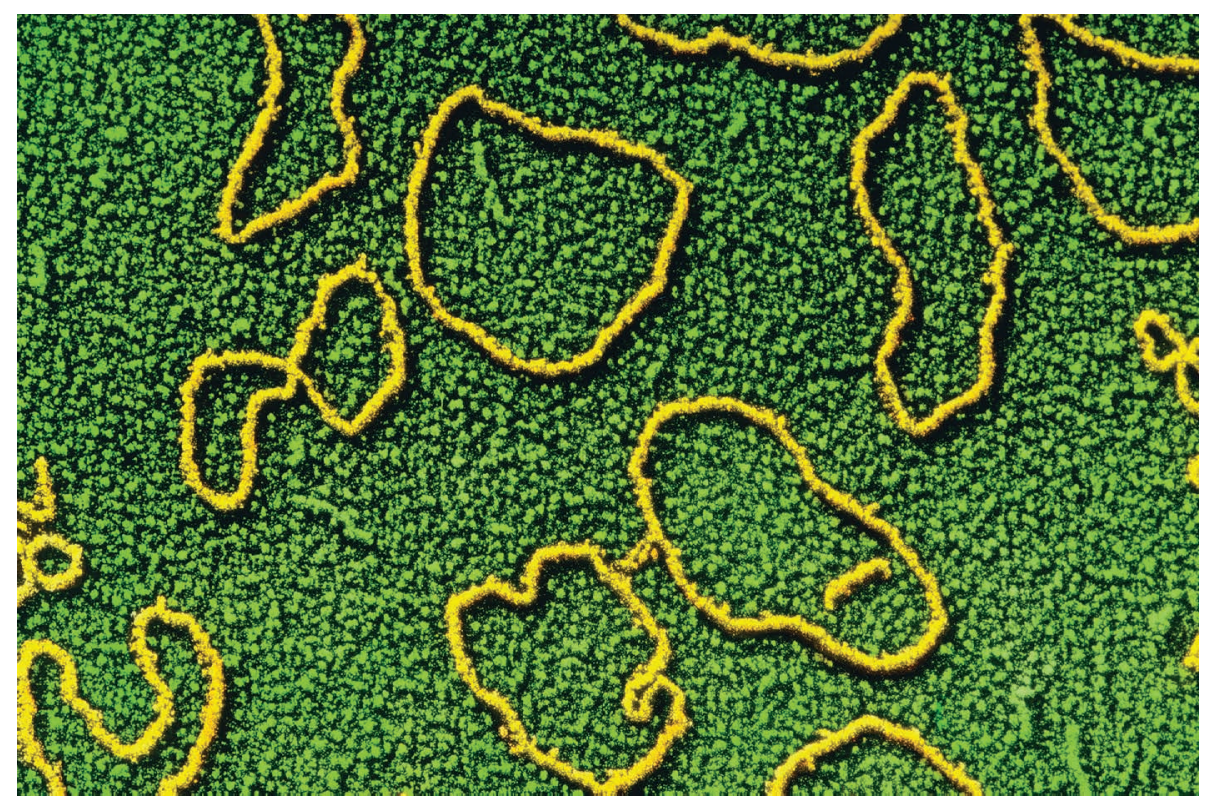

Circular DNA molecules called plasmids have been transformed into cellular-data recorders.

recorders. One, called CAMERA2, relies on modified CRISPR systems called base editors, developed by Liu's lab ${ }^{4}$ in 2016 , that can alter single DNA letters in the genome without relying on the cell's DNA-repair mechanisms. Liu and Tang used CAMERA2 to record up to four different stimuli in bacterial cells, including exposure to light and viruses, and the order in which the stimuli occurred.

The researchers also modified CAMERA2 to work in mammalian cells, recording changes directly in the genome rather than in plasmids. Tang and her colleagues hope to use the system to answer questions about how cells take on specific identities.

The CAMERA recorders will join a host of other cellular recorders under development. Synthetic biologist Harris Wang of Columbia
University Medical Center in New York City has been developing systems that he hopes to use to study microbes in the gut ${ }^{5}$.

And Junker's lab is working on a recorder to trace the developmental pathway of individual cells in zebrafish. He first thought of the approach a little over two years ago, he says. "I thought this was an exotic idea that I had," says Junker. "And suddenly everybody is doing it." -

1. Tang, W. \& Liu, D. R. Science http://dx.doi. org/10.1126/science.aap8992 (2018).

2. Chen, J. S. et al. Science http://dx.doi.org/10.1126/ science.aar6245 (2018).

3. Gootenberg, J. S. et al. Science http://dx.doi. org/10.1126/science.aaq0179 (2018).

4. Komor, A. C. et al. Nature 533, 420-424 (2016).

5. Sheth, R. U., Yim, S. S., Wu, F. L. \& Wang, H. H. Science http://dx.doi.org/10.1126/science. aao0958 (2017).

\title{
Indonesian funding agency short on cash
}

\author{
First dedicated fund has failed to raise enough money to \\ finance projects.
}

\section{BY DYNA ROCHMYANINGSIH}

I ndonesian scientists expecting to receive hundreds of thousands of dollars for research are stuck in limbo because the country's first dedicated science-funding agency is struggling to raise enough money.
After years of insufficient research funding, scientists were delighted when the Indonesian Science Fund (ISF) launched, in March 2016. Its aim was to boost investment in research and improve research quality. The following May, it opened up applications for grants worth up to 1.5 billion rupiah (US\$110,000) a year for
3 years. Scientists submitted 467 proposals.

Almost 18 months later, the ISF, which is managed by the Indonesian Academy of Sciences in Jakarta, says it has selected 10 projects that deserve to be funded, but does not have the money to give to researchers.

"The delay from ISF is very disappointing," says a researcher in Jakarta who was told in February 2017 that their application might be accepted, but was asked to revise their project budget. The scientist, who asked to remain anonymous for fear of jeopardizing the payment, says that they have not heard from the ISF since. "I am trying to find international research funding. But as long as we don't get any official rejection from ISF, it is unethical for us to send [our] research proposal to other funding agencies," they say. "In this situation, scientists are the victims."

Although the ISF seeks funds from a range of sources, including philanthropy and 